\title{
Multiscale mapping of the salt marshes using Sentinel-2, Dove and UAV imagery in the Bay of Mont-Saint-Michel
}

\author{
Antoine Collin 1,*, Dorothée James ${ }^{1}$, Antoine Mury ${ }^{1}$, Mathilde Letard ${ }^{1}$, Thomas Houët ${ }^{2}$, Hélène Gloria ${ }^{1}$ and Eric \\ Feunteun ${ }^{3}$ \\ 1 Ecole Pratique des Hautes Etudes - PSL University, 35800 Dinard, France; antoine.collin@ephe.psl.eu \\ 2 University of Rennes 2, CNRS LETG, 35000 Rennes, France; thomas.houet@univ-rennes2.fr \\ 3 Museum National d'Histoire Naturelle, Ecole Pratique des Hautes Etudes, CNRS BOREA, 35800 Dinard, \\ France; eric.feunteun@mnhn.fr \\ * Correspondence: antoine.collin@ephe.psl.eu
}

\begin{abstract}
The salt marshes, lying at the land-sea temperate interface, furnish a plethora of ecosystems services such as biodiversity niche support, ocean-climate change regulation, ornithology recreo-tourism or plant gathering by hand. They undergo significant worldwide losses due to their conversion into crop fields and to their spatial compression between the rising sea-level and the armoring shoreline. Their monitoring however requires to use a suite of remote sensing sensors to embrace the regional scale while capturing the plant details. This research innovatively adopts a multiscale approach using a cascading spaceborne and airborne process, from the 10-m Sentinel-2, through the 3-m Dove, to the 0.03-m unmanned airborne vehicle (UAV) imageries. The high to very high temporal resolution of the Sentinel-2 and Dove enabled to cover twenties and tens of $\mathrm{km}^{2}$ over five and four years, respectively, in the form of normalized difference vegetation index (NDVI) classes, associated with microphytobenthos, low, medium and high salt marsh vegetation, including the opportunistic Elyma genus. The NDVI was then modelled at the UAV scale (a few $\left.\mathrm{km}^{2}\right)$ using a three-layered NN prediction, providing the final near-infrared (NIR), and the intermediate red, green and blue reflectance imageries, calibrated/validated/tested with the Dove reflectance imageries $\left(R^{2}{ }_{\text {NIR }}=0.98, R^{2}{ }_{\text {red }}=0.88, R^{2}{ }_{\text {green }}=0.84\right.$, and $\left.R^{2}{ }_{\text {blue }}=0.90\right)$. The 100 fold increase in pixel size allowed to detect the decimeter-scale objects of the tidal flats and salt marshes, to enlarge the NDVI class ranges, and hold great promise to model other spectral bands at the UAV scale for further deeply enhancing the salt marsh mapping.
\end{abstract}

Keywords: spatiotemporal analysis; high to ultra high spatial resolution; high to very high temporal resolution; NDVI; NIR; neural network modelling, Bay of Mont-Saint-Michel

\section{Introduction}

Salt marshes consist of tidal wetlands at the land-sea interface in which complex interactions between shoots, roots, soil, freshwater and seawater processes occur [1]. These pivotal ecosystems provide numerous services, such as the biodiversity niche support (sentinel and umbrella plant species, benthic molluscs and crustaceans, insects, migratory and sedentary birds, fish nursery within tidal channels), the ocean-climate change regulation (hydrodynamic barrier against erosion and submersion, land fertilizer recycler, carbon sink, thus their "blue carbon" nickname, shared with mangroves and seagrasses), the ornithology recreo-tourism or plant gathering by hand $[2,3]$. Since the Holocene with the agriculture birth and emergence, these fertile areas were globally converted into crop fields. Nowadays, the coastal eutrophication continues to reduce salt marsh extents [4], but remains stable in the face of the sea-level rise [5]. Locally, salt marsh can undergo significant losses in China [6], affecting the sediment budget and even tide [7]. In the context of the global land and sea surface temperature warming, poleward shifts of the mangrove entail established competition with salt marshes in America and Australasia [8]. 
Given their important services, salt marshes deserve to be scrutinized along both the spatial and temporal study axes. The reliable monitoring of their spatial patterns is necessary to elucidate their endogenous and exogenous drivers. Cartographically, it is possible to turn back to the beginning of the XVIIIth century based on the dedicated salt marsh icon on the maps [9]. Following the ground triangulation of the salt marsh over more than two centuries, the 1950s airborne photographs improved the geolocation of the envelope along with the advent of the landscape ecology [10]. The addition of the airborne nearinfrared (NIR) information led to the interpretation of the salt marsh net primary productivity [11], paving the way to its implementation on a spaceborne platform (Landsat-4, [12]). The "vegetation index" ratioing the difference between the NIR and red with their addition gave birth to the normalized difference vegetation index (NDVI) applied to Landsat-1 over the USA Great Plains [13]. The NDVI-based Landsat-series enabled to monitor salt marshes across four decades, provided with (resampled) 60-m to (native) 30$\mathrm{m}$ pixel size [14]. More recently, the satellite Sentinel-2, launched in 2015, captured the NDVI at $10 \mathrm{~m}$ spatial resolution provided with a five-day revisit (compared to 16-day with Landsat-8), constituting valuable time-series to investigate the salt marsh evolution [15]. Since 2016, the Dove nano-satellites [16], each carrying a four-band optical sensor, embodied a technological leap given its daily revisit at 3-m pixel size [17].

The spaceborne salt marsh observation has also benefited from an increase in both spatial and spectral resolution with the WorldView-3 sensor, providing five visible, three NIR and eight mid-infrared bands at $0.3 \mathrm{~m}$ pixel size (the very high resolution, $[18,19]$ ). Usually restricted to active very fine-scale remote sensing, such as airborne topographic and/or bathymetric lidar [20], the salt marsh vegetation height and composition could have been reached using neural network (NN) predictive modelling [19]. By augmenting the spatial resolution, the three-band sensor conveyed by unmanned aerial vehicle (UAV) can leverage natural-colored imagery (red-green-blue, RGB) at ultra high resolution, ranging from the 0.01-m to 0.1-m pixel size [21]. This flexible platform, along the time axis, is strongly cost-efficient owing to the consumer-grade purchase and maintenance costs, but very frequently lacks the NIR band, meaningful for discriminating the salt marsh vegetation, soil, sediment and water. That spectral deficiency has been very recently closed by predicting the NIR response from RGB predictors using a fully connected NN spatiallyexplicit model [22].

Because remote sensing is a nexus of trade-offs, the spaceborne high spatial resolution, regional and airborne ultra-to-very high spatial resolution, local imageries, respectively, lose from the coarseness of the grain-size and the smallness of the scene. Even if those spatial specificities have been upgraded along with the temporal and spectral resolution, there is still no optimal sensor to spectrally discriminate submeter salt marsh structural and functional patterns at the week lag, that could match the salt marsh scale.

This research will adopt an original multiscale NDVI approach to both monitor the diachronic salt marsh evolution at high resolutions and predict the NIR, then NDVI, at ultra high resolution, over one of the largest salt marshes in Europe (Bay of Mont-SaintMichel, Figure 1). Spaceborne Sentinel-2 and Dove imageries will help quantify the spatially-explicit NDVI trend at 10 and 3-m pixel size, spanning five and four years, respectively. The UAV-borne senseFly RGB predictors will then be enriched with a modelled NIR band based on the Dove response and a multi-layered NN learning. Spatial-temporalspectral resolutions of the sensors and transferability of the modelling approach will be discussed in a context of the salt marsh monitoring and management. 


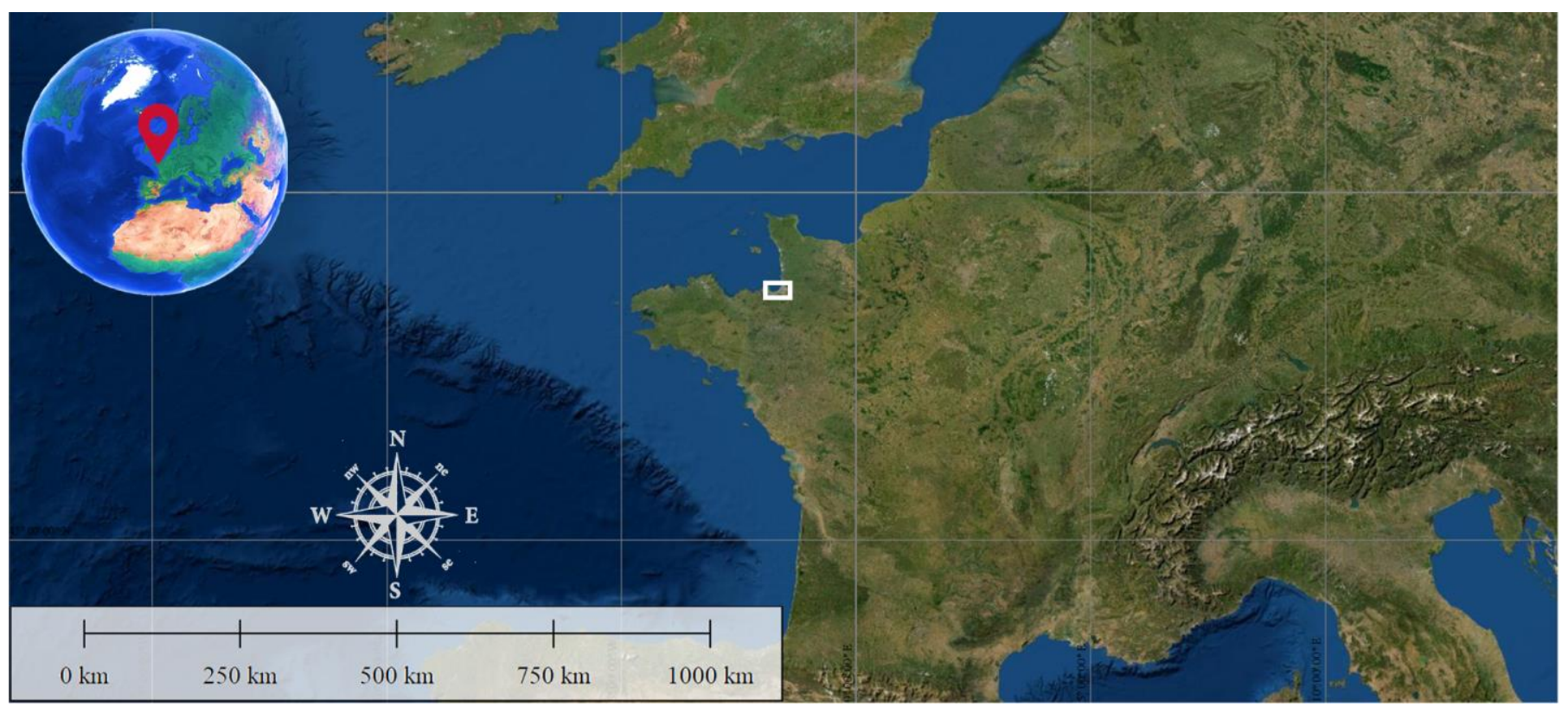

Figure 1. Location of the study site: Bay of Mont-Saint-Michel between Normandy and Brittany regions (France).

\section{Materials and Methods}

The methodological development of this research referred to a large-scale salt marsh area, very susceptible to encompass the plant and soil spectral variability, for the sake of transferability. Likewise, Sentinel-2, Dove and UAV imageries integrated into this study consist of the remote sensing data that are increasingly used, thus the enhancement of the method outreach.

\subsection{Study area}

The Bay of Mont-Saint-Michel's salt marshes lie both along Normandy and Brittany coasts in France $\left(48^{\circ} 38^{\prime} 05^{\prime \prime} \mathrm{N} ; 1^{\circ} 30^{\prime} 36^{\prime \prime} \mathrm{W}\right)$. Covering dozens of $\mathrm{km}^{2}$ in the highest part of the intertidal area (only submerged during high spring tides), these tidal ecosystems are subjected to three main rivers in the east; and to a clockwise gyre in the west (Figure 1). That spatial heterogeneity therefore separates an eastern estuary system, hydrologically dynamic, from a western bay system, calmer. Those meadows are classified as UNESCO natural heritage, since 1979, and benefit from the European protection as Natura 2000 sites for both "Habitats" and "Birds" directives. Birdlife International also outlined the Bay and its salt marshes as an "important zone for bird conservation". At the national scale, they are inventoried and listed as "natural zones for ecology, flora and fauna".

The use of those salt marshes is allowed for extensive saltbush lamb breeding and water bird hunting, attested by artificial shallow water bodies (Figure 2a).

\subsection{Imagery sources and processings}

This research adopts a top-down approach by increasingly focusing on the salt marshes, cascading from 10-m Sentinel-2 to 3-m Dove, in turn to 0.03-m UAV. The NDVI consists of the guideline within this multiscale study.

\subsubsection{Satellite Sentinel-2 optical data}

The monitoring of the whole salt marshes, at the Bay scale, was ensured by two Sentinel-2A multispectral imager (MSI) datasets, collected on 18 March 2016 (Figure 2a) and 1 April 2021 (Figure 2b). As interested in the visible and NIR spectrum intended for the NDVI product, the blue $(492 \pm 33 \mathrm{~nm})$, green $(560 \pm 18 \mathrm{~nm})$, red $(665 \pm 15 \mathrm{~nm})$ and NIR $(833$ $\pm 53 \mathrm{~nm}$ ) wavebands were investigated. They are provided with the finest Sentinel-2 pixel size, namely 10-m spatial resolution.

Both imageries were downloaded in the form of the L1C product, that is to say geometrically- and radiometrically-corrected at the top of atmosphere (TOA) reflectance. 
Using the Sentinel-2 toolbox, the atmosphere effect was compensated, enabling to convert the TOA reflectance into bottom of atmosphere (BOA) reflectance (the L2A product).

The NDVI was then computed for both dates following this formula [13]:

$$
\text { NDVI= (NIRBOAref }- \text { RedBOAref }) /(\text { NIRBOAref }+ \text { RedBOAref }) \text {, }
$$

where NIRвоAref and RedBOAref correspond to the Sentinel-2A bands centered at 833 and 665 $\mathrm{nm}$, orthorectified and adjusted to the BOA reflectance.

The five-year diachronic analysis established the trivial per-pixel difference of the NDVI products associated with both dates. Those dates were chosen to be the most distant while being captured at the closest seasonal time, here in the early spring.

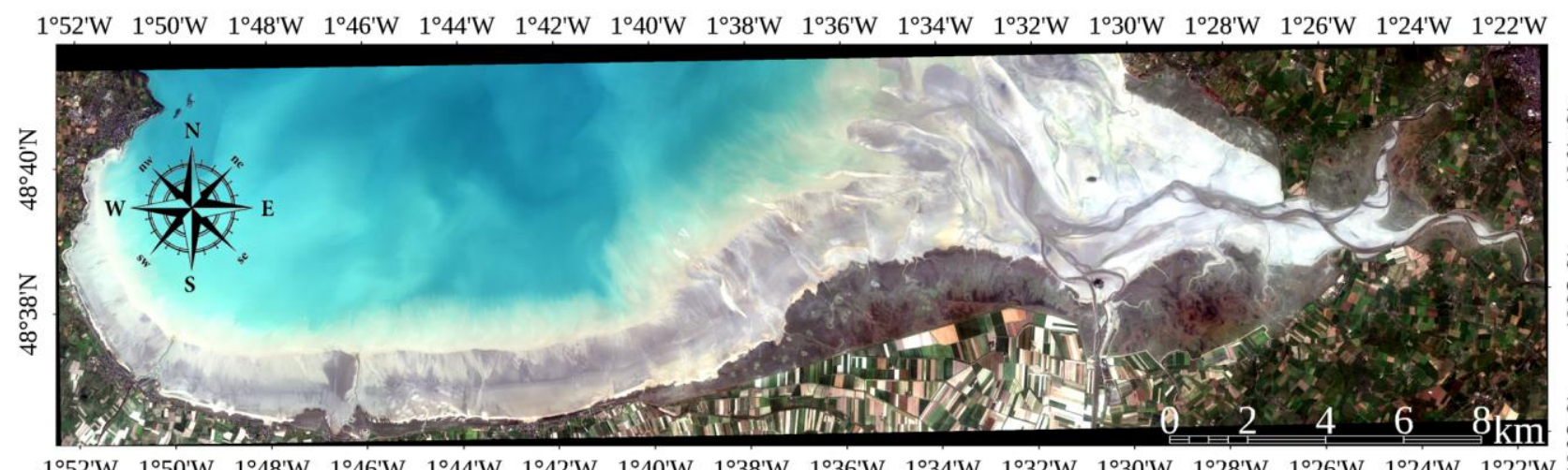

(a)

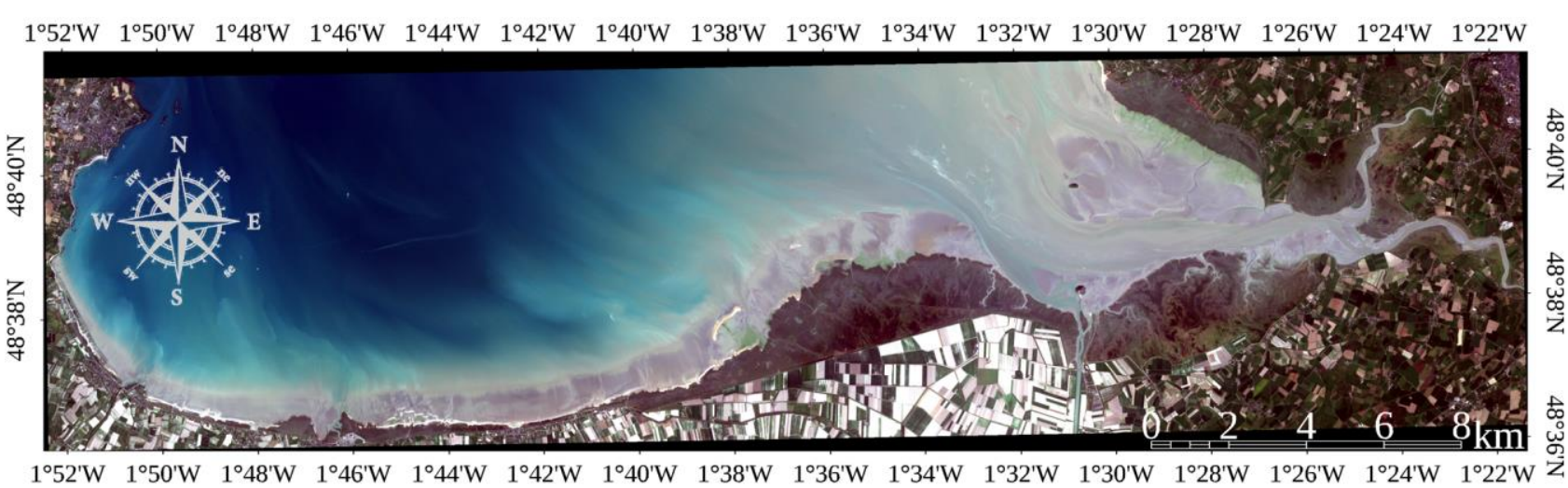

(b)

Figure 2. Sentinel-2A multispectral imager natural-colored imagery of the study site acquired on : (a) 18 March 2016; (b) 1 April 2021. Both imageries were orthorectified and radiometrically corrected to the bottom of reflectance.

\subsubsection{Nano-satellite Dove optical data}

Based on the large-scale Sentinel-2A information, the largest and most dynamic salt marsh area (centered at $48^{\circ} 38^{\prime} \mathrm{N} ; 1^{\circ} 35^{\prime} \mathrm{W}$ on the Figure 2) was examined at a finer scale using the hypertemporal Dove imagery [17], from the company Planet Labs. Two Dove imageries, provided with the Planetscope PS2 camera, were acquired on 1 June 2017 (Figure 3a) and 3 May 2021 (Figure 3b). With the overarching NDVI, the blue $(485 \pm 30 \mathrm{~nm})$, green $(545 \pm 45 \mathrm{~nm})$, red $(630 \pm 40 \mathrm{~nm})$ and NIR $(820 \pm 40 \mathrm{~nm})$ wavebands were examined at 3-m spatial resolution.

Geometric and radiometric corrections were applied to obtain the orthorectified BOA reflectance.

The NDVI was also calculated for each date (as distant as possible for this late spring season). The four-year difference was then per-pixel mapped. 


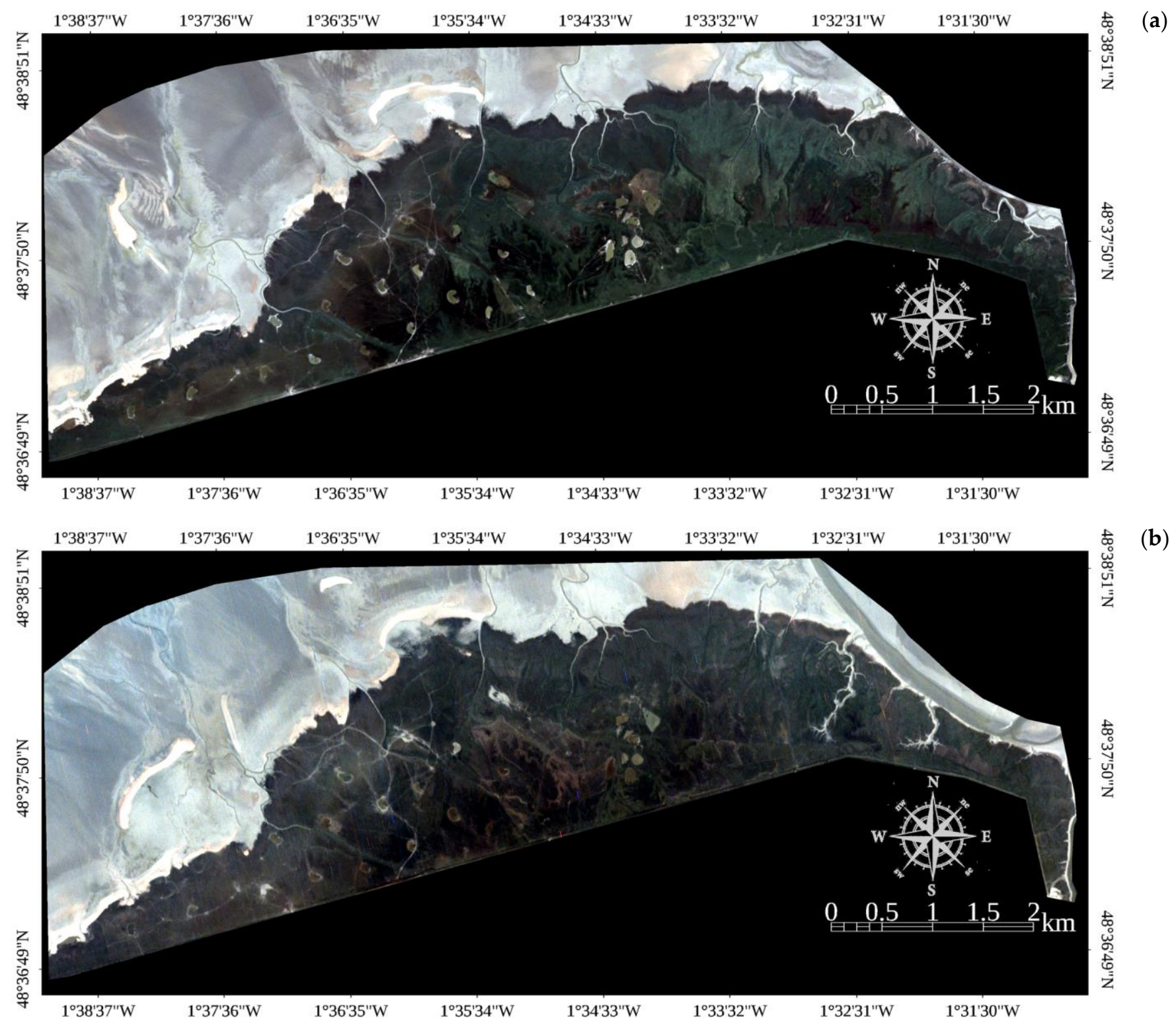

Figure 3. Dove Planetscope PS2 natural-colored imagery of the core of the study site acquired on : (a) 1 June 2017; (b) 3 May 2021. Both imageries were orthorectified and radiometrically corrected to the bottom of reflectance.

A third Dove imagery (Figure 4a) was additionally retrieved over the most extended and changing area (centered at $48^{\circ} 37^{\prime} 50^{\prime \prime} \mathrm{N}$; $1^{\circ} 36^{\prime} 35^{\prime \prime} \mathrm{W}$ on the Figure 3 ) to be purposed as the spectral response of the NN predictive modelling involving UAV natural-colored predictors. That imagery, taken on 11 July 2020 to be the closest to the UAV flight conducted on 8 July 2020, featured the same spectral and spatial specificities as well as geometric and radiometric corrections, as previously-mentioned. 


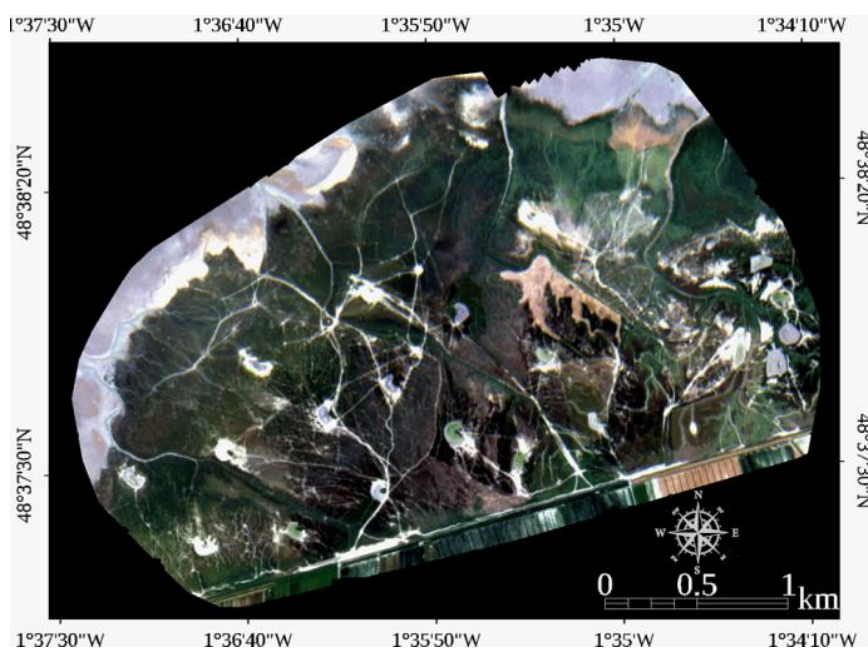

(a)

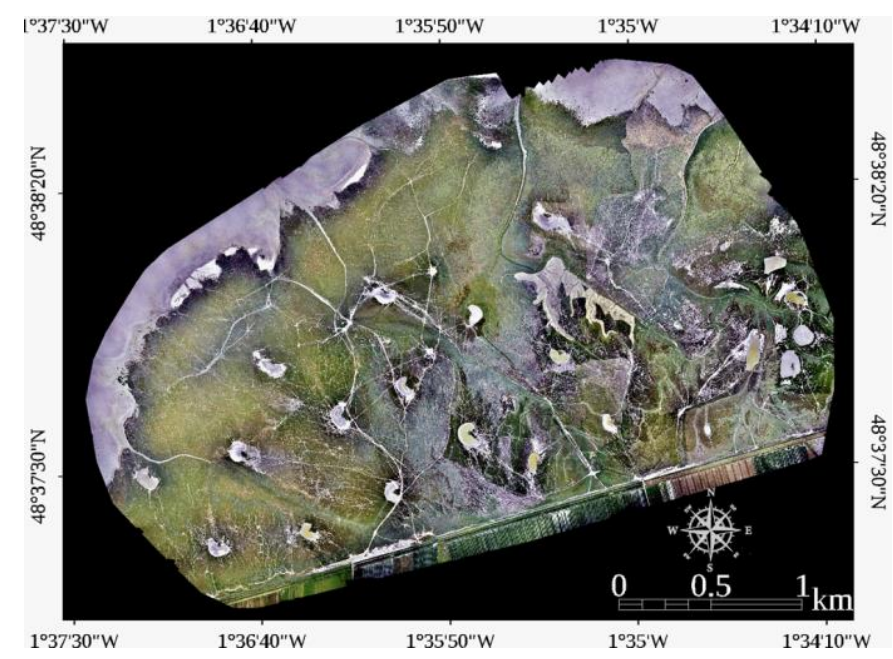

(b)

Figure 4. Natural-colored imagery derived from: (a) Dove Planetscope PS2, acquired on 11 July 2020; (b) unmanned airborne vehicle SODA, acquired on 8 July 2020.

\subsubsection{Unmanned aerial vehicle visible data}

By investigating the medium-scale Dove Planetscope PS2 information, the mutating zone was further analyzed at the local scale using the ultra high resolution UAV-borne senseFly "sensor optimized for drone application" (SODA) sensor. This 1" camera was mounted on a fixed-wing eBee UAV [21], whose the flight mission was planned at $120 \mathrm{~m}$ height (here, equivalent to the altitude), what corresponded to a $0.03-\mathrm{m}$ pixel size. The survey occurred on 8 July 2020, three days before the Dove acquisition.

As a conventional visible camera, the SODA sensor captured blue, green and red wavebands in the form of digital numbers (DN) coded into eight bits.

\subsection{Unmanned aerial vehicle optical modelling}

The NIR constitutes a compulsory term to solve for the NDVI formula. That waveband, slightly longer than the visible gamut, exists for the satellite Sentinel-2 and Dove sensors, but not for the UAV camera. By implementing a non-linear regression, it is very likely to predict the Dove NIR BOA reflectance response from the UAV RGB DN predictors, using artificial NN models [22].

\subsubsection{Two-scaled spectral datasets}

The potential to accurately estimate the satellite NIR BOA reflectance at the UAV scale depends on the relevance of the sampling strategy (Figure 5).

The proposed procedure started with a stack of the Dove NIR-RGB BOA reflectance with the UAV RGB DN based on the rigorous geolocation using ENVI 5.5 (L3Harris Geospatial Solutions, Broomfield, CO, USA). For each spectral satellite reflectance band to be predicted, a relevant pixel sampling was carried out:

- Slicing the spectral band into 75 evenly-spaced reflectance ranges;

- Saving the sliced areas as regions of interest;

- Computing and extracting the mean values for the four satellite and three UAV bands per slice;

- Randomly dividing the output matrix into 25 calibration, 25 validation and 25 test samples.

\subsubsection{Neural network regression}

Prior to estimate the NIR BOA reflectance from the UAV RGB DN, the B BOA, the G $\mathrm{BOA}$, the R BOA reflectances had to be predicted. Based on the band-specific stratified sampling, the NN model built a fully-connected one-layer perceptron, whose the (hidden) layer was composed of a single (hidden) neuron (or node) [24]. For each neuron, a sigmoid 
activation function, defined as a hyperbolic tangent function $(\mathrm{TanH})$, was generated as a linear regression of the RGB predictors:

$$
\mathrm{NN}\left(X_{i}\right)=\mathrm{Wi}_{\mathrm{i}} X_{\mathrm{i}}+\mathrm{C}
$$

where $\mathrm{NN}\left(X_{i}\right)$ is the predicted BOA reflectance of the spectral band $X_{i}, W_{i}$ is the sigmoid activation function of the DN spectral band $\mathrm{X}_{\mathrm{i}}$, and $\mathrm{C}$, an offset (see the first hidden layer in Figure 5).

Once the RGB datasets were properly estimated at the BOA reflectance level (see the second layer in the Figure 5), the NIR BOA reflectance can be modelled using a hidden layer with a single neuron linked with the three predicted BOA RGB reflectances (see the third layer in the Figure 5).

Unmanned Airborne Vehicle natural-colored imagery $(0.03 \mathrm{~m})$
Neural Network hidden layers

(calibrated/validated/tested with 4-band Planetscope imagery, $3 \mathrm{~m}$ )
Infrared imagery

$(0.03 \mathrm{~m})$

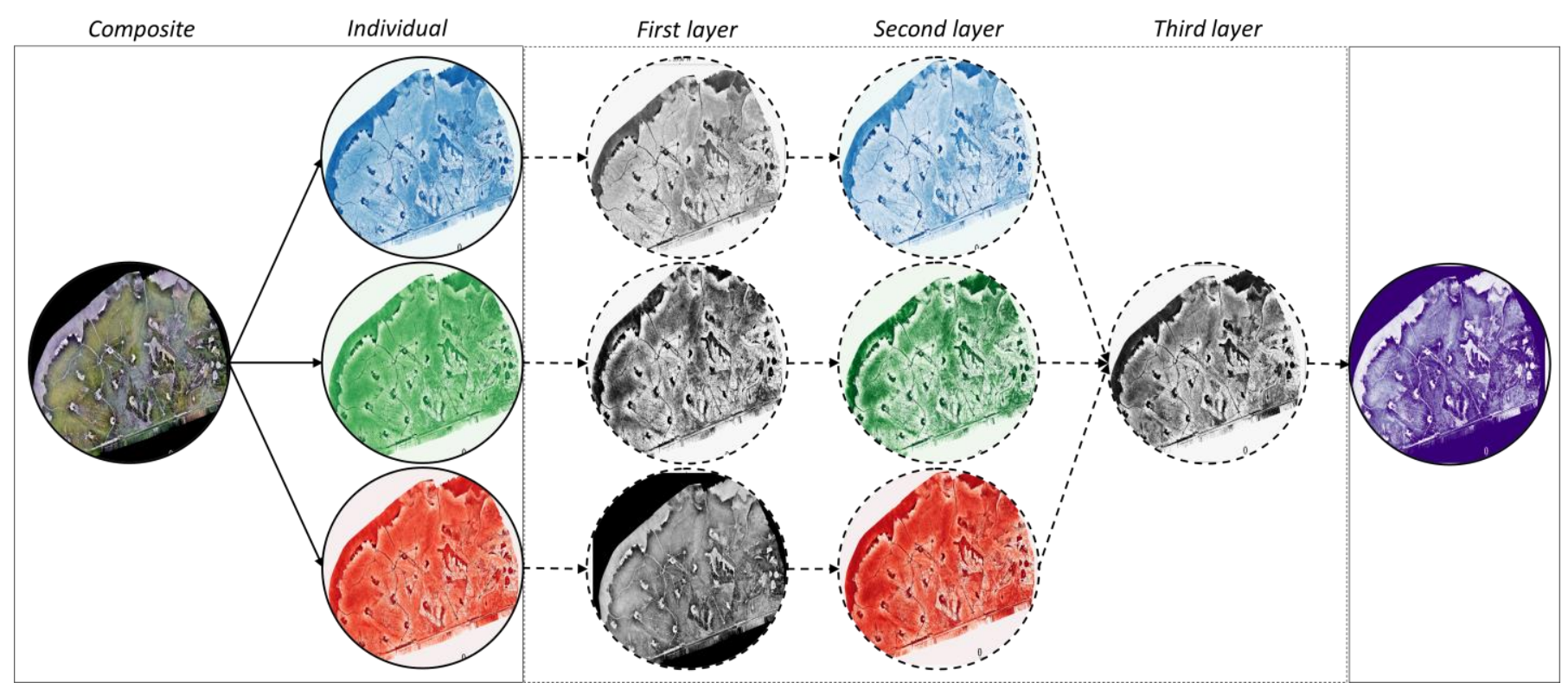

Figure 5. Flowchart describing how a 3-m satellite Dove Planetscope PS2 near-infrared imagery (bottom of atmosphere reflectance) can be spatially enhanced at $0.03-\mathrm{m}$ pixel size, using a $0.03-\mathrm{m}$ unmanned airborne vehicle natural-colored imagery (digital numbers) and a three-layer neural network calibrated/validated/tested with the satellite Planetscope blue - green - red - near-infrared imagery.

\section{Results}

The innovative multiscale mapping of the salt marshes in the Bay of Mont-SaintMichel relied, first, on the diachronic analysis of the five-year and four-year change in the NDVI using 10-m Sentinel-2 and 3-m Dove imageries, respectively, and second, on the prediction of the NDVI, using the 0.03-m UAV along with a NIR neural network modelling.

\subsection{Normalized Difference Vegetation Index change}

\subsubsection{Satellite Sentinel-2}

The computation of the NDVI products based on Sentinel-2A MSI showed divergences between 18 March 2016 (Figure 6a) and 1 April 2021 (Figure 6b) at the large scale of the Bay. The sea level was different due to the variation in the tide schedule. The crop fields, bushes, trees and salt marshes were significantly more vivid in March 2016 than in April 2021, as testified by the red predominance in March 2016. The NDVI classes greater than the 0 value indeed attained $241.64 \mathrm{~km}^{2}$ and $214.42 \mathrm{~km}^{2}$ for March 2016 and April 2021, respectively. By examining the NDVI classes greater than 0 with a 0.2 lag, the surface area was generally more important in March 2016 than in April 2021:

- $\quad 111.23 \mathrm{~km}^{2}$ versus $92.04 \mathrm{~km}^{2}$ for the [0-0.2] class; 
- $\quad 53.94 \mathrm{~km}^{2}$ versus $50.41 \mathrm{~km}^{2}$ for the [0.2-0.4] class;

- $\quad 53.20 \mathrm{~km}^{2}$ versus $54.14 \mathrm{~km}^{2}$ for the [0.4-0.6] class; and

- $\quad 23.26 \mathrm{~km}^{2}$ versus $17.84 \mathrm{~km}^{2}$ for the [0.6-0.8] class.
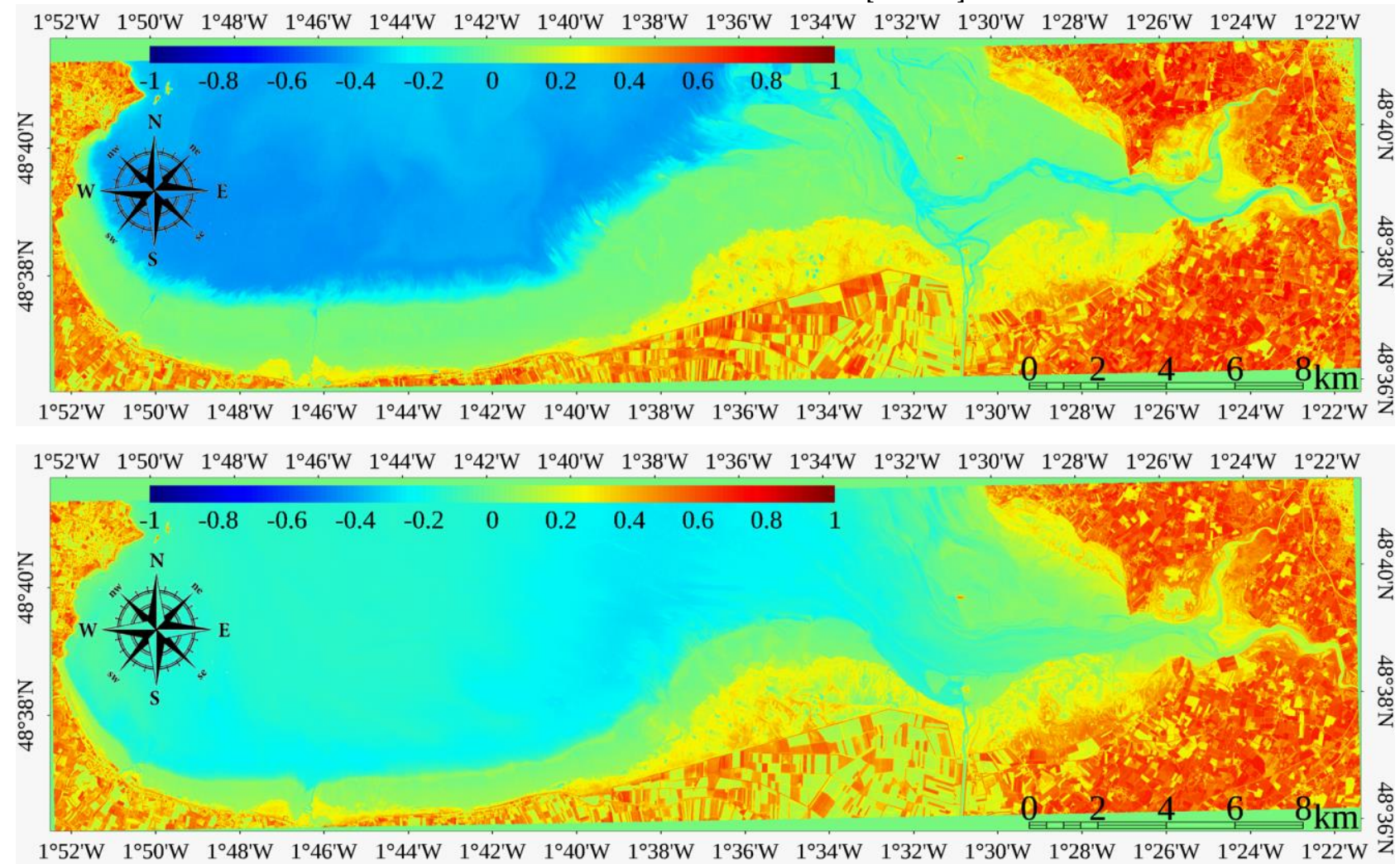

(b)

Figure 6. Sentinel-2A multispectral imager Normalized Difference Vegetation Index imagery of the study site acquired on : (a) 18 March 2016; (b) 1 April 2021.

Focused on the salt marshes (see the masking within Figure 7), the distribution of the NDVI class values varied between March 2016 and April 2021. The NDVI values lesser than 0 spanned smaller areas in March $2016\left(1.13 \mathrm{~km}^{2}\right)$ than in April $2021\left(1.55 \mathrm{~km}^{2}\right)$. Conversely, the NDVI values greater than 0 extended over a slightly larger overall area in March $2016\left(58.96 \mathrm{~km}^{2}\right)$ than in April $2021\left(58.53 \mathrm{~km}^{2}\right)$. However, this average concealed trends at the NDVI class level with a predominance in 2021 compared to 2016, except for the medium positive NDVI class:

- $\quad 27.41 \mathrm{~km}^{2}$ versus $25.35 \mathrm{~km}^{2}$ for the [0-0.2] class;

- $\quad 24.63 \mathrm{~km}^{2}$ versus $29.69 \mathrm{~km}^{2}$ for the [0.2-0.4] class;

- $\quad 6.18 \mathrm{~km}^{2}$ versus $3.72 \mathrm{~km}^{2}$ for the [0.4-0.6] class; and

- $\quad 0.31 \mathrm{~km}^{2}$ versus $0.19 \mathrm{~km}^{2}$ for the [0.6-0.8] class.

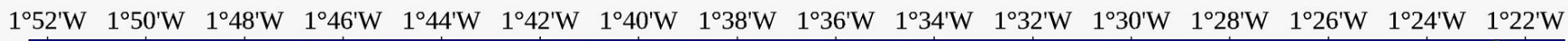

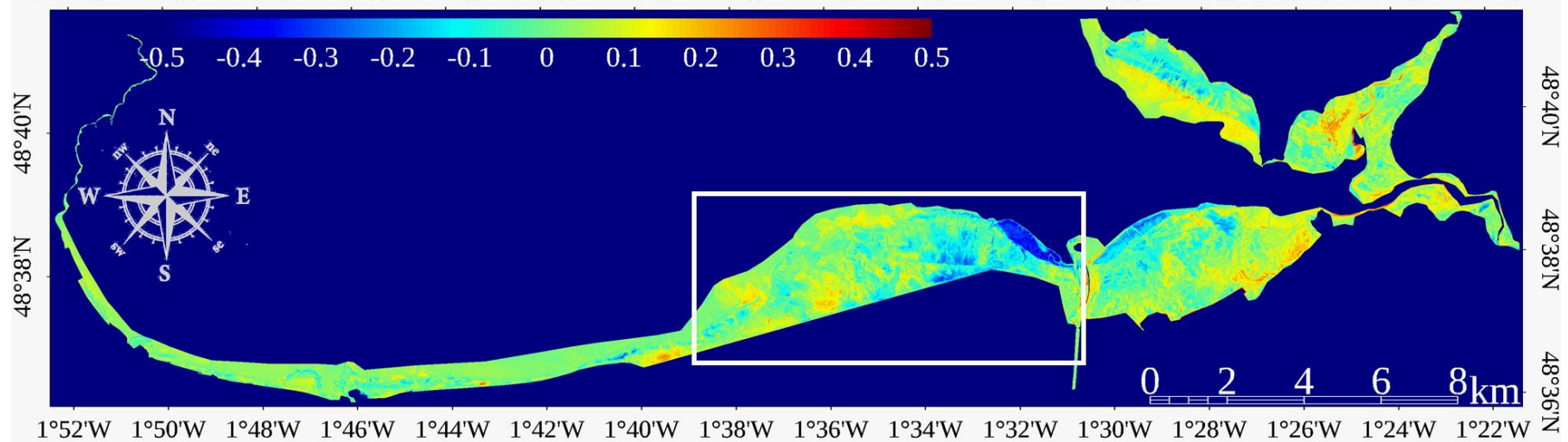


Figure 7. Difference in the Normalized Difference Vegetation Index of the Sentinel-2A multispectral imager datasets between 1 April 2021 and 18 March 2016. The white rectangle identifies the dynamic area, that was further investigated with Dove Planetscope PS2 imageries.

The difference in NDVI between 2021 and 2016 early springs (Figure 7) was characterized by a gentle increase in negative and very high positive [0.6-0.8] NDVI values, stronger augmentation for low [0-0.2] and high positive [0.4-0.6] NDVI values, and a significant decline in the medium positive [0.2-0.4] NDVI values.

The white rectangle on the Figure 7 outlined the area provided with the deepest contrast in the salt marsh 2021-2016 change, that was further examined with the Dove imageries.

\subsubsection{Nano-satellite Dove}

The computation of the NDVI products based on Dove Planetscope PS2 revealed distinctions between 1 June 2017 (Figure 8a) and 3 May 2021 (Figure 8b) at the medium scale of the most dynamic salt marsh. The NDVI values seemed, at first sight, to diminish in that four-year period, as attested by the loss in orange in May 2021. The easternmost salt marsh zone has eroded at the benefit of a river channel $\left(48^{\circ} 38^{\prime} \mathrm{N} ; 1^{\circ} 31^{\prime} 30^{\prime \prime} \mathrm{W}\right)$. In contrast, the central western front has significantly prograded $\left(48^{\circ} 38^{\prime} \mathrm{N} ; 1^{\circ} 36^{\prime} \mathrm{W}\right)$.

The NDVI classes lesser than the 0 value waned (from $11.15 \mathrm{~km}^{2}$ in June 2017 to 11.06 $\mathrm{km}^{2}$ in May 2021), whereas the NDVI classes greater than 0 waxed (from $14.55 \mathrm{~km}^{2}$ in June 2017 to $14.64 \mathrm{~km}^{2}$ in May 2021). By examining the NDVI classes above 0 at the 0.2 lag, the surface area was much wider in 2021 than in 2017 for the [0-0.2] class $\left(10.24 \mathrm{~km}^{2}\right.$ versus $\left.1.74 \mathrm{~km}^{2}\right)$, but was more cramped for both the [0.2-0.4] $\left(4.39 \mathrm{~km}^{2}\right.$ versus $\left.10.35 \mathrm{~km}^{2}\right)$ and [0.4-0.6] $\left(0.005 \mathrm{~km}^{2}\right.$ versus $\left.2.46 \mathrm{~km}^{2}\right)$ classes.

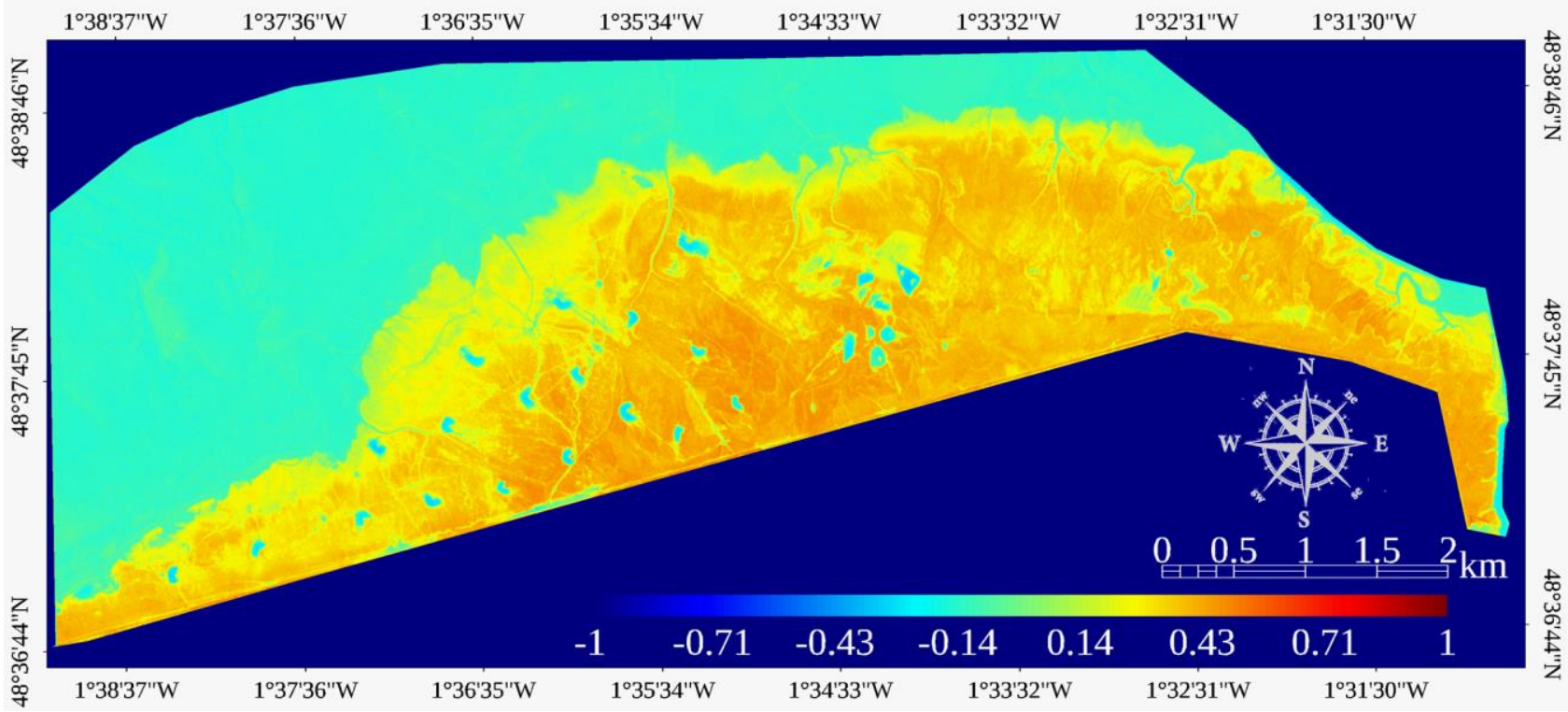




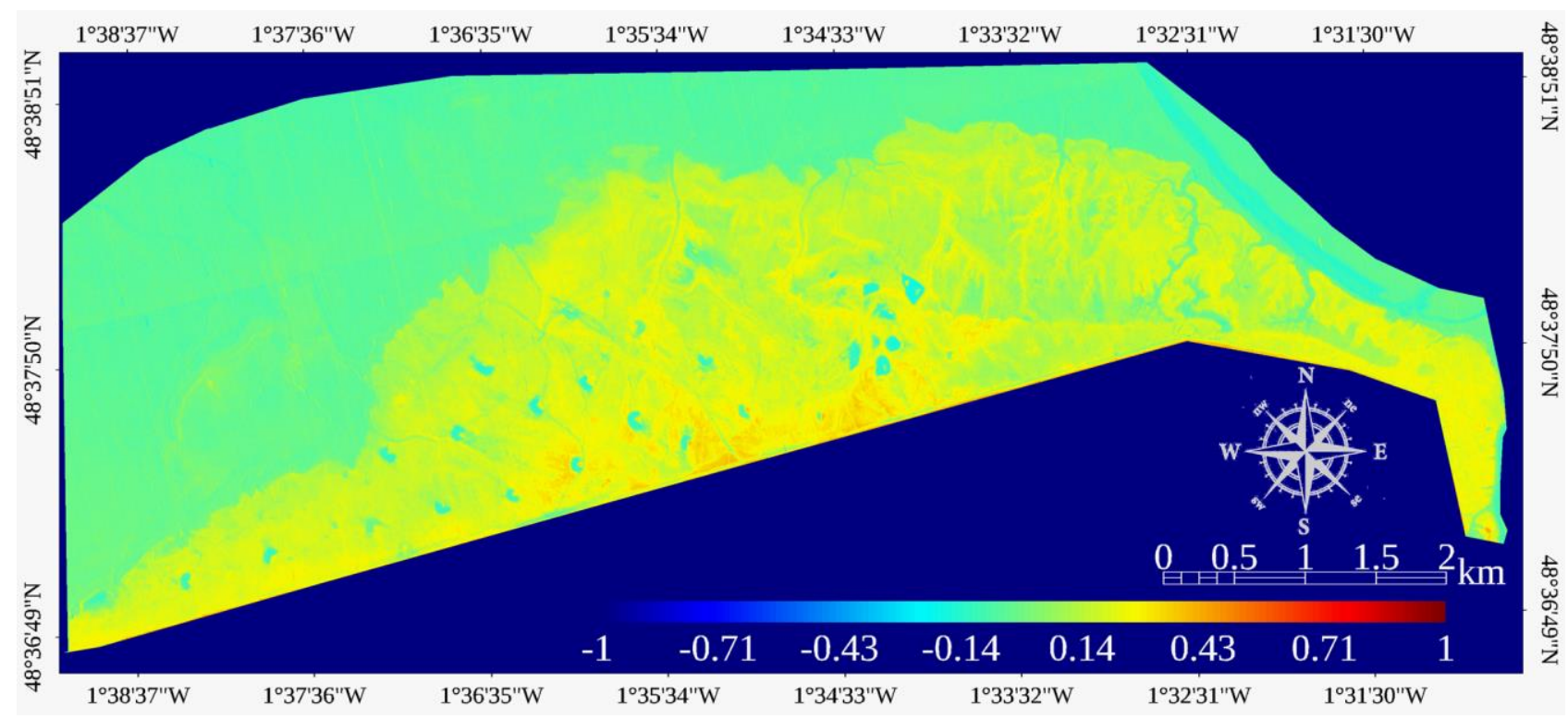

(b)

Figure 8. Dove Planetscope PS2 Normalized Difference Vegetation Index imagery of the core of the study site acquired on : (a) 1 June 2017; (b) 3 May 2021.

The difference in NDVI between 2021 and 2017 late springs (Figure 9) was featured by a slight rise in negative [0.6-0.8] NDVI values, the greatest increase for low positive [0$0.2]$ NDVI values, and a tangible decrease in the medium [0.2-0.4] and high [0.4-0.6] positive NDVI values.

The black rectangle on the Figure 9 delineated the hybrid area provided with obvious losses and gains in the NDVI values in the salt marsh during the 2021-2017 period. That zone was further investigated with the UAV imagery.

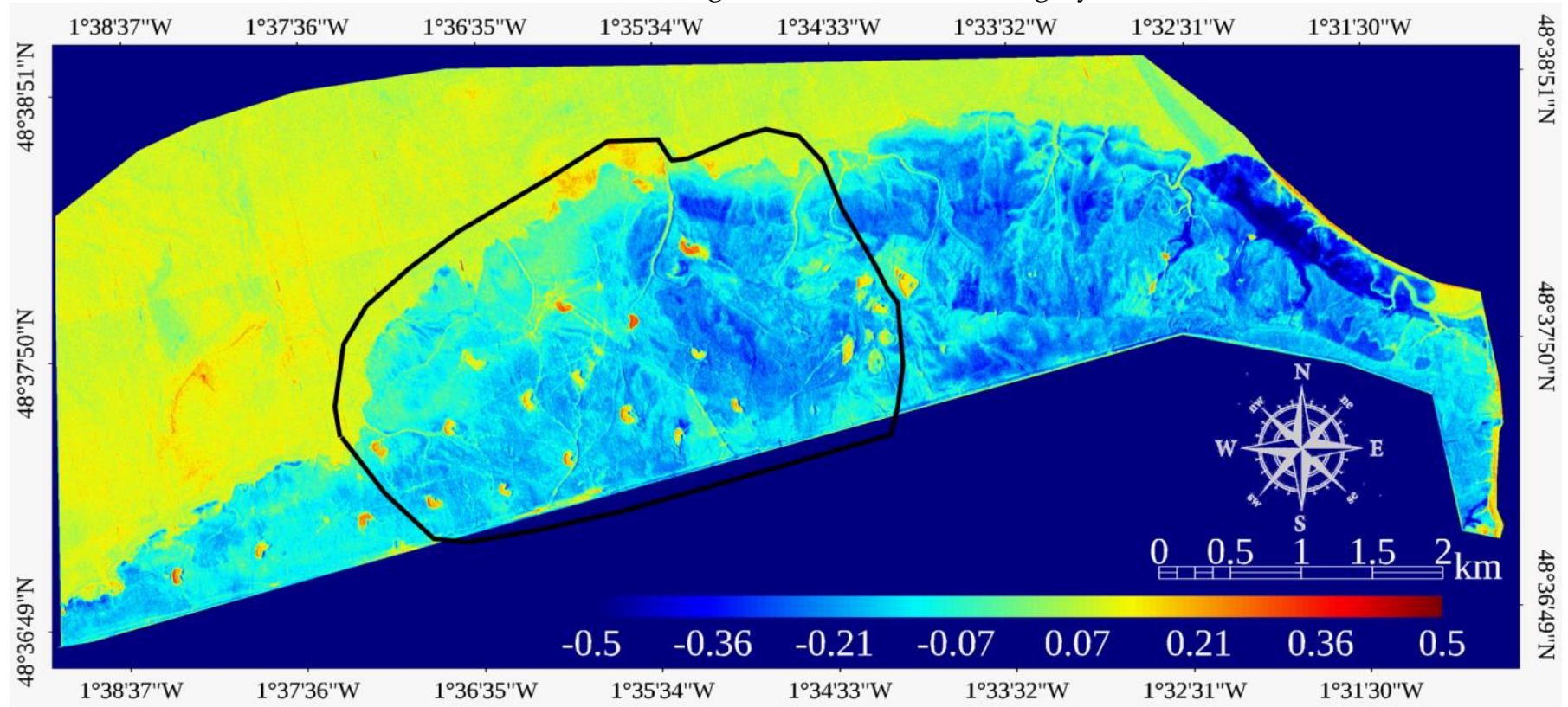

Figure 9. Difference in the Normalized Difference Vegetation Index of the Dove Planetscope PS2 imageries between 3 May 2021 and 1 June 2017. The black polygon identifies the salt marsh area, that was surveyed by an unmanned airborne vehicle on 8 July 2020.

\subsection{Normalized Difference Vegetation Index prediction}

\subsubsection{Unmanned aerial vehicle near-infrared}

The study of the NDVI spatial patterns was not trivial and required to be able to create a NIR band at the UAV fine scale. Based on a previous development established on a NN predictive modelling of the NIR reflectance from UAV RGB predictors [22], the UAV 
NIR BOA reflectance was predicted from UAV RGB BOA reflectances, themselves predicted from Dove RGB BOA reflectances. The Table 1 summarized the performances of the three individual visible predictions, as well as the final NIR prediction (see Figure 5). The green, red and blue BOA reflectances were very well modelled by their akin oneneuroned one-layered NN model, ranging from 0.84 to 0.90 in independent test $\mathrm{R}^{2}$. The NIR BOA reflectance was extremely well predicted by its three-neuroned one-layered NN model, topping at 0.98 in $\mathrm{R}^{2}$.

Table 1. Results of the neural network predictive modelling for each spectral band as a function of the randomly-divided datasets.

\begin{tabular}{ccccccc}
\hline & \multicolumn{2}{c}{ Calibration } & \multicolumn{2}{c}{ Validation } & \multicolumn{2}{c}{ Test } \\
\hline & $\mathbf{R}^{2}$ & RMSE & $\mathbf{R}^{2}$ & $\mathbf{R M S E}^{2}$ & $\mathbf{R}^{\mathbf{2}}$ & $\mathbf{R M S E}^{-}$ \\
\hline Blue & 0.85 & 64.13 & 0.97 & 26.59 & $\mathbf{0 . 9 0}$ & 51.26 \\
\hline Green & 0.93 & 43.54 & 0.82 & 71.21 & $\mathbf{0 . 8 4}$ & 68.55 \\
\hline Red & 0.87 & 84.59 & 0.85 & 91.76 & $\mathbf{0 . 8 8}$ & 82.70 \\
\hline Near-infrared & 0.99 & 150.27 & 0.98 & 177.61 & $\mathbf{0 . 9 8}$ & 162.73
\end{tabular}

The predicted values of the blue, green and red NN models were combined to predict the NIR BOA reflectance values (using the Dove Planetscope PS2 imagery, Figure 10a), following the below formula:

NIRBoAref $=2755.53+2025.37 \times($ TanH $(0.5 \times(12.12-0.02 \times$ BlueвоAref $+0.01 \times$ GreenвOAref $-0.02 \times$ Red BOAref $))$,

where all NIR, Blue, Green and Red variables correspond to the predicted BOA reflectance spectral variables.

The equation was thereafter applied to the UAV pixel in order to produce the NIR BOA reflectance at $0.03-\mathrm{m}$ spatial resolution (Figure 10b). Even though the general spatial patterns were qualitatively similar between the 3-m and 0.03-m NIR BOA products, such as for the artificial water bodies for hunting and the tidal flats, the 100fold-magnified details computed for the salt marsh enabled to elucidate the complex network of the sheeps and hunters' pathways, and also the higher vegetation reflectance at the forefront and around the water bodies. Conversely, the more subtle reflectance signatures allowed to identify Dove homogeneous vegetated areas, that were decomposed in a larger diversity of plant reflectance, thus taxonomy and/or phenology.

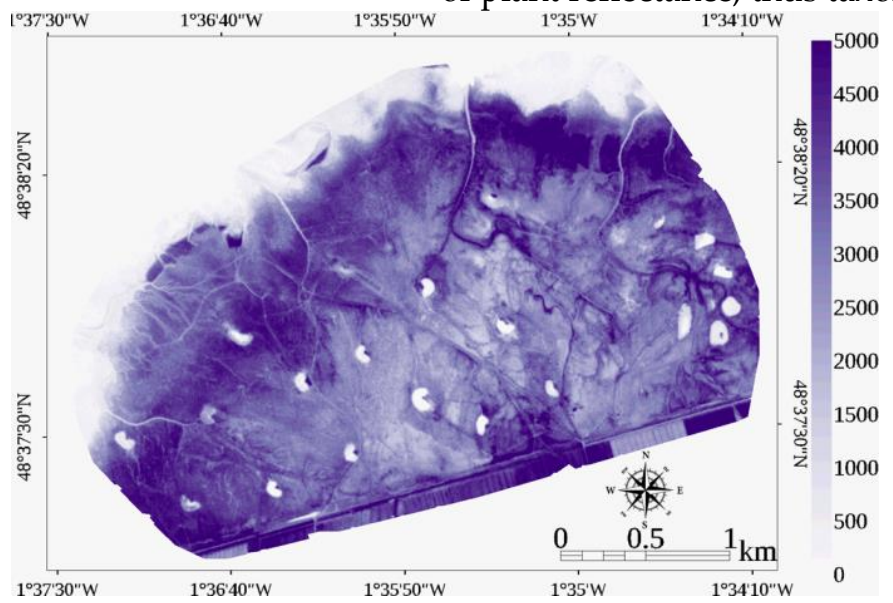

(a)

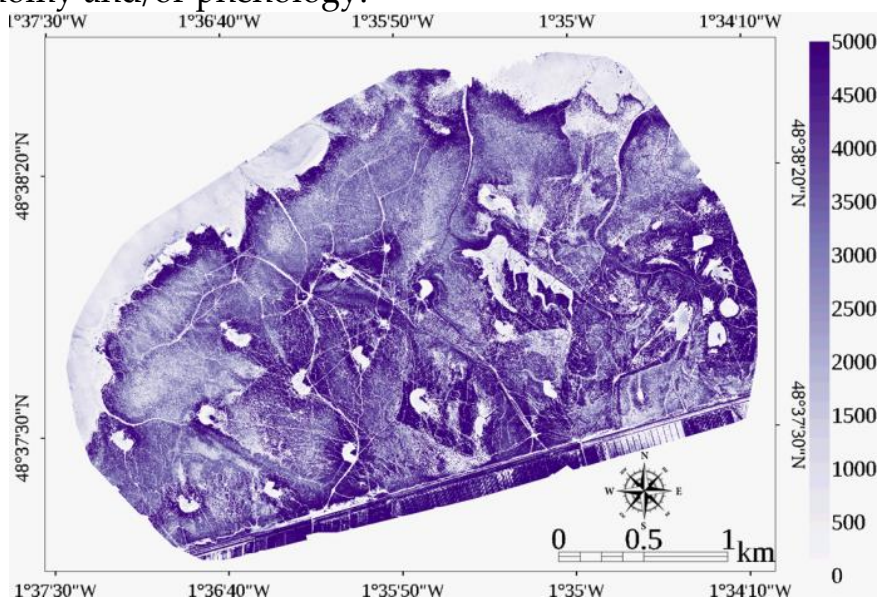

(b)

Figure 10. Near-infrared imagery derived from: (a) Dove Planetscope PS2 bottom of atmosphere reflectance, acquired on 11 July 2020; (b) unmanned airborne vehicle bottom of atmosphere reflectance, modelled from the 8 July 2020 acquisition.

The creation of the NIR BOA reflectance band at the Dove (Figure 11a) and UAV (Figure 11b) spatial scale made the NDVI calculation possible (Figure 11a and b, respectively). At the level of the whole salt marsh area (first line of the Figure 11), the spatial variability of the NDVI associated with the innovative UAV-based imageries was 
obviously much stronger than this tied to the Dove-based data, labelled with larger even areas. To highlight the great information enhancement derived from the UAV, two zoomins were realized (the second and third lines of the Figure 11 matching the small black rectangles in the first line of the Figure 11), incontrovertibly contrasting the homogeneity of the 3-m Dove NDVI, hardly fluctuating, with the tremendous complexity of the 0.03-m UAV NDVI.
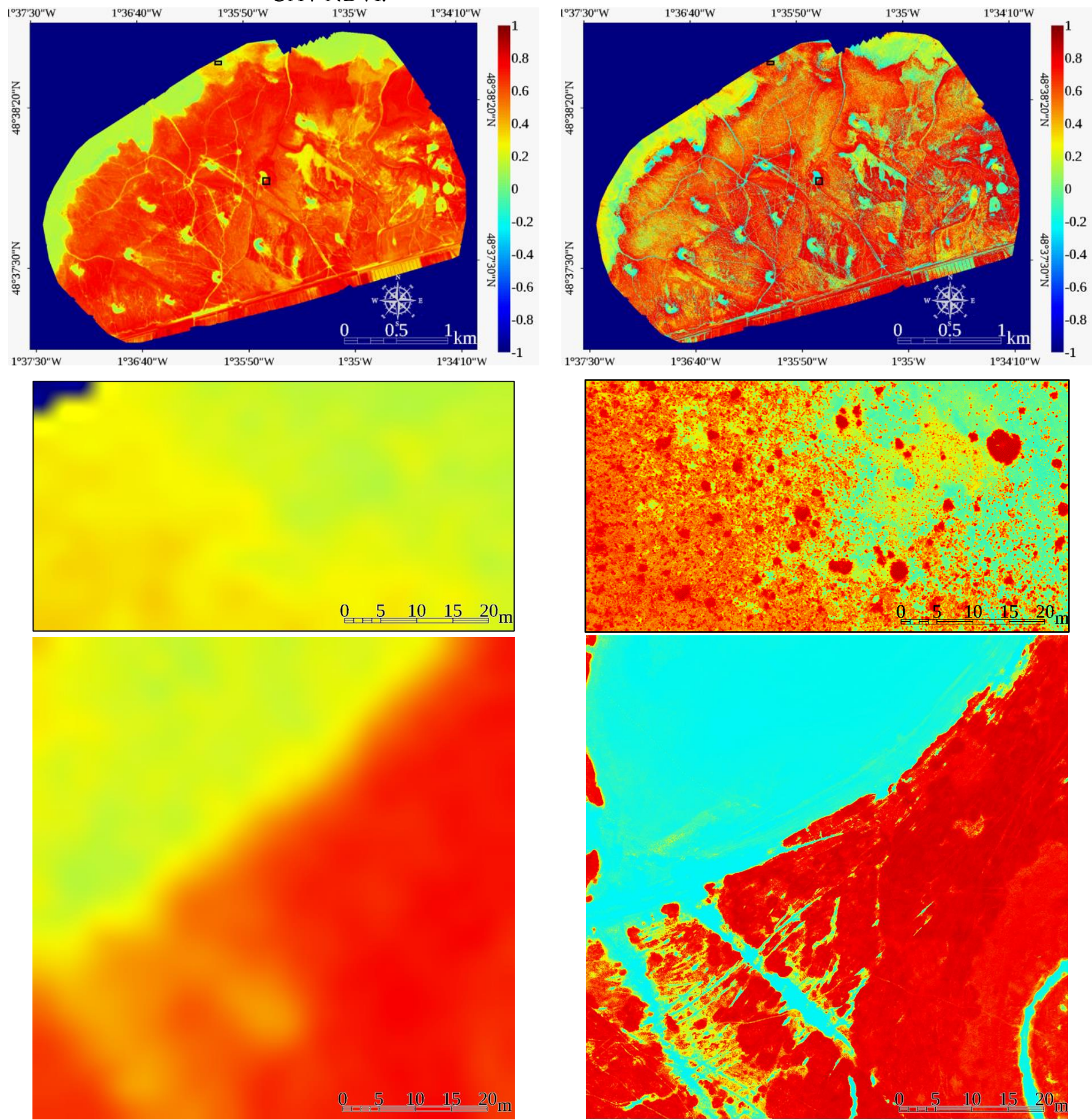

(a)

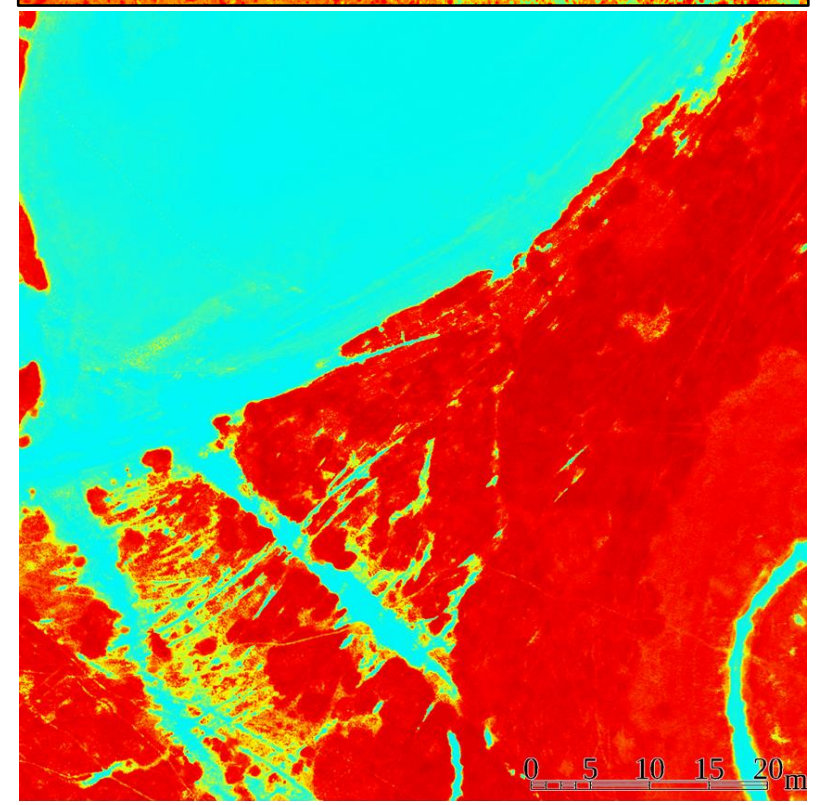

(b)

Figure 11. Normalized Difference Vegetation Index imagery derived from: (a) Dove 3-m Planetscope PS2, acquired on 11 July 2020; (b) SODA 0.03-m UAV, acquired on 8 July 2020. Black rectangles that lie on the first line of the figure correspond to the enlargements displayed on the second and third lines of the figure.

Quantitatively, the number of the NDVI classes and the surface area covered within classes (defined at the $0.2 \mathrm{lag}$ ) conspicuously varied from the Dove to the UAV products. The Dove dataset ranged from [-0.2-0] to [0.8-1.0], encapsulating six classes, while that of 
the UAV comprised seven classes, by adding the [-0.4--0.2] to the previous ones. Even if the relative distribution within common classes followed the same tendency for both datasets, the UAV detected more negative, medium and extreme positive NDVI classes at the detriment of the high and very high positive classes.

\section{Discussion}

\subsection{Salt marsh spatiotemporal patterns}

\subsubsection{Satellite-based salt marsh spatial analysis}

According to the results derived from the 10-m Sentinel-2 NDVI, the surface covered by vegetation tend to average $59 \mathrm{~km}^{2}$ for the whole Bay of Mont-Saint-Michel, thus including Brittany and Normandy coastal ecosystems. That area encompassed sub-areas associated with diverse NDVI signatures, such as low, medium, high and very high values. A part of the low NDVI [0-0.2] values might stem from the phytoplankton flourishing on the close tidal flats and channels [25], wandering in the salt marsh meadows. A large but not exclusive part of the medium NDVI class [0.2-0.4] might emerge from the low salt marsh plant genera, such as Spartina, Salicornia and Suaeda [26,27]. Likewise, high NDVI class [0.4-0.6] partly arose from the medium salt marsh flagship species Halimione portulacoides [18]. Finally, very high NDVI class [0.6-0.8] might contain the spectral signatures of the high salt marsh genera, such as Puccinellia, Festuca, Aster and Limione [28,29]. In that latter NDVI class could also be integrated the genus Elymus [30], that tends to thrive over the topographically medium and high salt marsh at the detriment of the traditional species and genera [31]. That Elymus expansion, between 1984 and 2013, within the Bay of Mont-Saint-Michel was hypothesized as an ecological response of the watershed change in agricultural land-use, thus in eutrophication (especially nitrates).

The previous authors established that the salt marshes in 2013 extended over $42 \mathrm{~km}^{2}$ based on a thorough photo-interpretation. Our NDVI outcomes seemed to over-estimate those findings. However, by keeping medium, high and very high NDVI classes (those related to the salt marsh vegetation) and by simply removing the half of the surface covered by the low NDVI class [0-0.2], which was very likely to merge microphytobenthos and sparse low salt marsh vegetation at $10 \mathrm{~m}$ pixel size, the results reached $46 \mathrm{~km}^{2}$.

At the most dynamic salt marsh scale, the 3-m Dove NDVI classification, issued from slicing in 2017, clearly shed light on the predominance of the negative and the positive medium NDVI class, compared to the low and the high NDVI classes. The enhancement of the spatial resolution might therefore better discriminate the microphytobenthos from the low salt marsh vegetation, provided that the salt marsh analyzed by Dove was representative of all salt marshes examined by Sentinel- 2 .

The inaccuracies derived from the manual outlining of other studies and our NDVI continuous indicator could be further overcome by implementing a supervised classification at very high resolution using machine learning [19], including deep learning [32].

\subsubsection{Satellite-based salt marsh temporal evolution}

At the Bay scale, the NDVI change, between 2016 and 2021, underlined a salt marsh expansion trend around the three river mouths (east), a diminution south of Mont-SaintMichel, and another development slightly westward (see Figure 7). The latter erosion/accretion salt marsh movement could be explained by the flushing effect of the recentlybuilt (2009) dam just south of Mont-Saint-Michel. The overall salt marsh progradation, during those five years, forms the recent part of a continuing process, observed since the first aerial photographs in 1947: 2021 (46 km², our study), 2013 (42 km², [31]), 1996 (24.15 $\mathrm{km}^{2}$, [33]), 1980 (21.84 km², [33]), and 1947 (12.88 km², [33]). That Bay-scale time-series will be duly enriched with the high temporal resolution provided by the $10-\mathrm{m}$ Sentinel-2A MSI so as to identify the stability or the variability in the velocity of the salt marsh general progradation and local erosion/accretion, facing the anthropocenic changes [34].

The diachronic analysis of the five-year NDVI time-series has unveiled that the early spring salt marshes at the Bay scale gained low ([0-0.2]: $\left.+2.06 \mathrm{~km}^{2}\right)$ and high ([0.4-0.6]: $\left.+2.45 \mathrm{~km}^{2} ;[0.6-0.8]:+0.11 \mathrm{~km}^{2}\right)$ salt marsh vegetation, but lost medium $\left([0.2-0.4]:-5.06 \mathrm{~km}^{2}\right)$ 
one. That pattern might be explained by the trend in H. portulacoides loss at the benefit of the low salt marsh, which prograded, and of the Elymus high even very high vegetation boosted by the eutrophication.

The NDVI change of the representative salt marsh between late spring 2017 and middle spring 2021 was also characterized by an increase in low salt marsh vegetation ([0-0.2]: $\left.+8.50 \mathrm{~km}^{2}\right)$, a decrease in medium salt marsh vegetation ([0.2-0.4]: $\left.-5.96 \mathrm{~km}^{2}\right)$, both like Sentinel-2 results, but a contrasting decline in high vegetation ([0.4-0.6]: $-2.45 \mathrm{~km}^{2}$ ). This reduction in high vegetation could be corroborated with the fact that the focused salt marsh did not well represent the Elymus spread insofar as the studied area was relatively remote from the three rivers likely to convey the excessive nitrate inputs. The variation in the high vegetation NDVI signature could also stem from the phenological distance occurring between the late spring 1 June and the middle spring 3 May.

The augmentation of the low salt marsh vegetation might also be reinforced by the natural landward migration of the crescent-like sandy dunes that are visible on the Figure 9. Originated from a $2-\mathrm{km}^{2}$ seaward biogenic reef (located in the lower intertidal area, close to the subtidal limit), erected by the honeycomb worm Sabelleria alveolata [35], sediment pulses of calcareous sand are actuated by the combination of stormy waves and strong tidal currents, and cross the intertidal area in averaged 30 years [36]. When the biogenic sandy dunes get closer to the salt marsh forefront (hundreds of meters), the hydrodynamic conditions become calmer [28], what triggers an increase of rate sedimentation, in turn facilitating the colonization of the pioneer salt marsh species, such as Spartina, Salicornia and Suaeda. Like with Sentinel-2, the very high temporal resolution Dove satellites embody key imagery to build continuous time-series, that have the potential to neatly link the ecology of the most extended coastal animal reef in Europe, seaward, with one of the broadest vegetal meadow in Europe, landward, through a mobile landform.

\subsection{Salt marsh spatial modelling at ultra high resolution}

\subsubsection{Spectral predictive modelling at ultra high resolution}

The great performance of the predictive NN modelling of the NIR BOA reflectance helped to produce the NDVI at an unprecedented spatial resolution over the salt marshes of the Bay of Mont-Saint-Michel. That scientific advance enabled to detect a NDVI class [0.4--0.2], invisible to the Dove imagery, and to better distribute the pixels in the NDVI classes, by eroding the high and very high positive classes, and by fueling the negative, medium and extreme positive classes: [0-0.2]: -1.21 ha; [0.2-0.4]: 29.45 ha; [0.4-0.6]: -85.82 ha; [0.6-0.8]: -82.58 ha.; [0.8-1.0]: +36.87 ha. Those refinements will straightforwardly meliorate the diagnosis of the ecological structuration and functioning of the salt marsh, laying the foundation of a spatialized health state indicator.

That indicator would be all the more robust if it relies on additional spectral bands, such as the red edge, "squeezed" between the red and NIR, that is encompassed in the SuperDove PS2.SD satellite imagery. Furthermore, the SuperDove PSB.SD imagery even captures the purple, called coastal blue [431-452 nm], two green bands [513-549 nm] and [547-583 nm], yellow [600-620 nm], red [650-680 nm], red edge [697-713 nm], and NIR [845-885 nm]. Along with the 0.3-m six-band Pleiades Neo, the 0.3-m eight-band WorldView-2 and WorldView-3, the 3-m PSB.SD imagery modelled at the UAV-scale hold great promise to create optical multispectral ultra high resolution imagery at low cost. An even cost-efficient alternative would be to scale the visible and NIR spectral bands tied to Sentinel-2A MSI at the UAV pixel size, while bearing in mind that the scaling process will not shift imagery from $3 \mathrm{~m}$ (or $0.3 \mathrm{~m}$ ) to $0.03 \mathrm{~m}$, but from $10 \mathrm{~m}$ to $0.03 \mathrm{~m}$, what could lie on a very strong assumption of the spectro-spatial continuity.

\subsubsection{Height predictive modelling at ultra high resolution}

The NN predictive modelling of the NIR and other spectral optical bands will definitely aid in elaborating ecological indicators such as vegetation, soil or water continuous indices. Calibrated and validated by the topographic LiDAR height, the NN modelling even successfully predicted the salt marsh vegetation and elevation height [19]. Despite its reference status to monitor the coastal elevation [37] and composition [20], an airborne 
LiDAR survey remains costly. The spaceborne LiDAR, such as the topo-bathymetric ICESat-2, could be a much more affordable solution to sample salt marsh vegetation height and elevation, while keeping in mind that the footprint approximately reaches $10 \mathrm{~m}$ diameter [38]. Otherwise, those height and elevation could also be computed by the photogrammetric procedure intricately linked with the UAV planning survey [39]. Additionally to the UAV-scaled multispectral BOA reflectance bands (see 4.2.1.), the information of the vegetation height and elevation will have high potential to provide decisive cues to classify the salt marsh at the species level.

\section{Conclusions}

This paper shed light on the mapping of the salt marsh using a cascading process of the state-of-the-art remote sensing technologies, from the 10-m Sentinel-2A MSI to the 0.03-m UAV, through the 3-m Dove Planetscope PS2 imageries.

The Sentinel-2 and Dove multispectral BOA reflectance helped to monitor NDVI classes at the Bay (twenties of $\mathrm{km}^{2}$ ) and the salt marsh (tens of $\mathrm{km}^{2}$ ) scales, respectively. Their high and very high temporal resolution enabled to build their diachronic analysis over five (2016-2021) and four (2017-2021) years, respectively. Findings of both scales were discussed in the continuity of older studies, as well as hydrological, hydrodynamic, ecologi$\mathrm{cal}$ and socio-economic drivers. The NDVI classes were approached to discriminate microphytobenthos, low, medium and high salt marsh vegetation, including the opportunistic Elyma genus.

The NDVI was very satisfactorily modelled at the UAV scale $\left(a\right.$ few $\left.\mathrm{km}^{2}\right)$ using a three-layered NN prediction, providing the final NIR, and the intermediate red, green and blue BOA reflectance imageries, calibrated/validated/tested with the Dove BOA reflectance imageries $\left(\mathrm{R}^{2} \mathrm{NIR}=0.98, \mathrm{R}^{2}{ }_{\text {red }}=0.88, \mathrm{R}^{2}{ }_{\text {green }}=0.84\right.$, and $\left.\mathrm{R}^{2}{ }_{\text {blue }}=0.90\right)$. The 100 fold gain in pixel size not only allowed to seize the decimeter-scale objects of the tidal flats and salt marshes, but better distribute the NDVI values, by increasing the negative, medium and extreme positive values, that were under-estimated, and by decreasing the high and very high positive values, that were over-estimated by the 3-m Dove BOA reflectance imageries.

Author Contributions: The individual contributions of the authors were as follows: conceptualization, A.C.; methodology, A.C.; software, T.H., A.C; validation, D.J., A.M, M.L, A.C. and T.H.; formal analysis, A.C.; investigation, E.F. and A.C.; resources, E.F., T.H., H.G. and A.C.; data curation, D.J. and A.C.; writing-original draft preparation, H.G. and A.C.; writing-review and editing, A.C.; visualization, T.H. and A.C.; supervision, E.F. and A.C.; project administration, E.F., H.G. and A.C.; funding acquisition, E.F. All authors have read and agreed to the published version of the manuscript.

Funding: This research received no external funding. The APC was internally funded by the coastal geoecological laboratory.

Data Availability Statement: Sentinel-2A MSI data were freely provided by the European Space Agency Copernicus Open Access Hub.

Acknowledgments: We deeply acknowledge European Space Agency, Planet@, and French Office for the Biodiversity for their support in imagery acquisition.

Conflicts of Interest: The authors declare no conflict of interest.

\section{References}

1. Kirwan, M.L.; Guntenspergen, G.R. Feedbacks between inundation, root production, and shoot growth in a rapidly submerging brackish marsh. J Ecology 2012, 100(3), 764-770.

2. Rendón, O.R.; Garbutt, A.; Skov, M.; Möller, I.; Alexander, M.; Ballinger, R.; Beaumont, N. A framework linking ecosystem services and human well-being: Saltmarsh as a case study. People and nature 2019, 1(4), 486-496.

3. Loconsole, D.; Cristiano, G.; De Lucia, B. Glassworts: from wild salt marsh species to sustainable edible crops. Agriculture 2019, 9(1), 14.

4. Deegan, L.A.; Johnson, D.S.; Warren, R.S.; Peterson, B.J.; Fleeger, J.W.; Fagherazzi, S.; Wollheim, W.M. Coastal eutrophication as a driver of salt marsh loss. Nature 2012, 490(7420), 388-392. 
5. Kirwan, M.L.; Megonigal, J.P. Tidal wetland stability in the face of human impacts and sea-level rise. Nature 2013, 504(7478), 5360.

6. Gu, J.; Luo, M.; Zhang, X.; Christakos, G.; Agusti, S.; Duarte, C.M.; Wu, J. Losses of salt marsh in China: trends, threats and management. Estuarine, Coastal and Shelf Science 2018, 214, 98-109.

7. Donatelli, C.; Ganju, N.K.; Zhang, X.; Fagherazzi, S.; Leonardi, N. Salt marsh loss affects tides and the sediment budget in shallow bays. Journal of Geophysical Research: Earth Surface 2018, 123(10), 2647-2662.

8. Saintilan, N.; Rogers, K.; McKee, K.L. The shifting saltmarsh-mangrove ecotone in Australasia and the Americas. In Coastal Wetlands, Elsevier, 2019, pp. 915-945.

9. Godet, L.; Pourinet, L.; Joyeux, E.; Verger, F. Dynamique spatiale et usage des schorres de l'Anse de l'Aiguillon de 1705 à nos jours. Enjeux de conservation d'un patrimoine naturel littoral marin. Cybergeo: European Journal of Geography 2015.

10. Russell, R.J. (University of Baton Rouge, Louisiana, US); Morgan, J.P. (University of Baton Rouge, Louisiana, US). Trafficability and Navigability of Delta-Type Coasts. Trafficability and Navigability of Louisiana Coastal Marshes. Photo-Interpretation Keys of Selected Coastal Marshland Features, 1952.

11. Stroud, L.M.; Cooper, A.W. Color-infrared aerial photographic interpretation and net primary productivity of a regularly flooded North Carolina salt marsh. Water Resources Research Institute of the University of North Carolina, 1969.

12. Hardisky, M.A.; Daiber, F.C.; Roman, C.T.; Klemas, V. Remote sensing of biomass and annual net aerial primary productivity of a salt marsh. Remote Sensing of Environment 1984, 16(2), 91-106.

13. Rouse, J.W.; Haas, R.H.; Schell, J.A.; Deering, D.W. Monitoring vegetation systems in the Great Plains with ERTS. NASA special publication 1974, 351(1974), 309.

14. Lopes, C.L.; Mendes, R.; Caçador, I.; Dias, J.M. Assessing salt marsh extent and condition changes with 35 years of Landsat imagery: Tagus Estuary case study. Remote Sensing of Environment 2020, 247, 111939.

15. Sun, C.; Li, J.; Cao, L.; Liu, Y.; Jin, S.; Zhao, B. Evaluation of Vegetation Index-Based Curve Fitting Models for Accurate Classification of Salt Marsh Vegetation Using Sentinel-2 Time-Series. Sensors 2020, 20(19), 5551.

16. Planet Team. Planet Application Program Interface: In Space for Life on Earth. San Francisco, CA, 2017.

17. Collin, A.; Durozier, T.; Hervouet, G.; Costa, S. Détecter le processus de dépoldérisation par l'observation satellite à très haute résolution temporelle. In 16th SAGEO, 5-7 May 2021; 250-252.

18. Collin, A.; Lambert, N.; James, D.; Etienne, S. Mapping wave attenuation induced by salt marsh vegetation using WorldView3 satellite imagery. Revista de investigación Marina 2018, 25(2), 67-69.

19. Collin, A.; Lambert, N.; Etienne, S. Satellite-based salt marsh elevation, vegetation height, and species composition mapping using the superspectral WorldView-3 imagery. International Journal of Remote Sensing 2018, 39(17), 5619-5637.

20. Collin, A.; Long, B.; Archambault, P. Salt-marsh characterization, zonation assessment and mapping through a dual-wavelength LiDAR. Remote Sensing of Environment 2010, 114(3), 520-530.

21. Mury, A.; Collin, A.; Houet, T.; Alvarez-Vanhard, E.; James, D. Using multispectral drone imagery for spatially explicit modeling of wave attenuation through a salt marsh meadow. Drones 2020, 4(2), 25.

22. Collin, A.; James, D.; Mury, A.; Letard, M.; Guillot, B. Predicting the Infrared UAV Imagery Over the Coast. ISPRS-International Archives of the Photogrammetry, Remote Sensing and Spatial Information Sciences 2021, 43, 149-156.

23. Mury, A.; Collin, A.; James, D. Morpho-Sedimentary Monitoring in a Coastal Area, from 1D to 2.5 D, Using Airborne Drone Imagery. Drones 2019, 3(3), 62.

24. Heermann, P.D.; Khazenie, N. Classification of Multispectral Remote Sensing Data Using a Back-Propagation Neural Network. IEEE Transactions on Geoscience and Remote Sensing 1992, 30 (1), 81-88.

25. Torrecilla, E.; Piera, J.; Pons, S.; Aymerich, I.F.; Vilamala, A.; Arcos, J.L.; Plaza, E. Mapping marine phytoplankton assemblages from a hyperspectral and Artificial Intelligence perspective. In Ocean's 10 IEEE, Sydney, Australia, 2010, May; IEEE, pp. 1-7.

26. Proença, B.; Frappart, F.; Lubac, B.; Marieu, V.; Ygorra, B.; Bombrun, L.; Sottolichio, A. Potential of high-resolution Pléiades imagery to monitor salt marsh evolution after Spartina invasion. Remote Sensing 2019, 11(8), 968.

27. Domínguez-Beisiegel, M.; Castañeda, C.; Mougenot, B.; Herrero, J. Analysis and mapping of the spectral characteristics of fractional green cover in saline wetlands (NE Spain) using field and remote sensing data. Remote Sensing 2016, 8(7), 590.

28. Mury, A.; Collin, A.; Etienne, S.; Jeanson, M. Wave attenuation service by intertidal coastal ecogeosystems in the Bay of MontSaint-Michel, France: Review and meta-analysis. Estuaries and Coastal Zones in Times of Global Change 2020, 555-572.

29. Belluco, E.; Camuffo, M.; Ferrari, S.; Modenese, L.; Silvestri, S.; Marani, A.; Marani, M. Mapping salt-marsh vegetation by multispectral and hyperspectral remote sensing. Remote sensing of environment 2006, 105(1), 54-67.

30. Taramelli, A.; Valentini, E.; Cornacchia, L.; Monbaliu, J.; Sabbe, K. Indications of dynamic effects on scaling relationships between channel sinuosity and vegetation patch size across a salt marsh platform. Journal of Geophysical Research: Earth Surface 2018, 123(10), 2714-2731.

31. Valéry, L.; Radureau, A.; Lefeuvre, J.C. Spread of the native grass Elymus athericus in salt marshes of Mont-Saint-Michel bay as an unusual case of coastal eutrophication. Journal of Coastal Conservation 2017, 21(3), 421-433.

32. Collin, A.; Letard, M.; Andel, M.; Sharma, S. Object-based mangrove mapping using submeter superspectral WorldView-3 imagery and deep convolutional neural network. In IEEE International Geoscience and Remote Sensing Symposium, 12-16 July $2021 ; 7362-7365$.

33. Bonnot-Courtois, C.; Fournier, J.; Dréau, A. Recent morphodynamics of shell banks in the western part of the Bay of Mont-SaintMichel (France)/Morphodynamique actuelle des bancs coquilliers dans la partie occidentale de la baie du Mont-Saint-Michel (France). Géomorphologie: relief, processus, environnement 2004, 10(1), 65-79. 
34. Letard, M.; Collin, A.; James, D.; Mury, A. Trajectoire socio-écologique d'une commune de la Baie du Mont-Saint-Michel entre 1947 et 2014. In 16th SAGEO, 5-7 May 2021; 63-74.

35. Collin, A.; Dubois, S.; Ramambason, C.; Etienne, S. Very high-resolution mapping of emerging biogenic reefs using airborne optical imagery and neural network: the honeycomb worm (Sabellaria alveolata) case study. International Journal of Remote Sensing 2018, 39(17), 5660-5675.

36. Collin, A.; Boymond, C.; Dubois, S. How the largest coastal animal reef facilitate one of the broadest vegetal meadow in Europe: the mineral hyphen. In International Temperate Reefs Symposium, 2023; submitted.

37. Mury, A.; Collin, A.; Jeanson, M.; James, D.; Gloria, H.; Pastol, Y.; Etienne, S. Mapping nature-based marine flooding risk using VHR wave, airborne LiDAR and satellite imagery: the case study of the Dol Marsh (Bay of Mont-Saint-Michel, France). Journal of Coastal Research 2020, 95(SI), 743-747.

38. Le Quilleuc, A.; Collin, A.; Jasinski, M.; Devillers, R. Very high-resolution satellite derived bathymetry and habitat mapping using Pleaides-1 and ICESat-2. Remote Sensing 2021, (submitted).

39. James, D.; Collin, A.; Mury, A.; Letard, M.; Guillot, B. UAV Multispectral Optical Contribution to Coastal 3D Modelling. In IEEE International Geoscience and Remote Sensing Symposium IGARSS, 2021; 7951-7954. 